\title{
Multicentric Lesion
}

National Cancer Institute

\section{Source}

National Cancer Institute. Multicentric Lesion. NCI Thesaurus. Code C94771.

A term that usually refers to cancer growth and is defined by the presence of multiple lesions, each originating from a different clonal cellular population. 